Abstracta Iranica Abstracta Iranica

Revue bibliographique pour le domaine irano-aryen

Volume 25 | 2004

Comptes rendus des publications de 2002

\title{
Northern Talysh. München, Lincom Europa, 2000, 94 p. (Languages of the world. Materials ; 380).
}

\section{Vincent Hachard}

\section{(2) OpenEdition}

12 Journals

\section{Édition électronique}

URL : http://journals.openedition.org/abstractairanica/4150

DOI : 10.4000/abstractairanica.4150

ISSN : 1961-960X

Éditeur :

CNRS (UMR 7528 Mondes iraniens et indiens), Éditions de l'IFRI

\section{Édition imprimée}

Date de publication : 15 mai 2004

ISSN : 0240-8910

\section{Référence électronique}

Vincent Hachard, "Northern Talysh. München, Lincom Europa, 2000, 94 p. (Languages of the world. Materials ; 380). », Abstracta Iranica [En ligne], Volume 25 | 2004, document 35, mis en ligne le 15 mars 2006, consulté le 25 septembre 2020. URL : http://journals.openedition.org/abstractairanica/4150 ; DOI : https://doi.org/10.4000/abstractairanica.4150

Ce document a été généré automatiquement le 25 septembre 2020.

Tous droits réservés 


\title{
Northern Talysh. München, Lincom Europa, 2000, 94 p. (Languages of the world. Materials ; 380).
}

\author{
Vincent Hachard
}

Spécialiste des langues caucasiques orientales et de typologie fonctionnelle, l'A. nous livre ici le résultat d'une enquête de terrain de 1986 consacrée à une langue iranienne occidentale mais relevant selon lui de l'aire linguistique caucasienne du sud-est (p. 37), le tâlechi (tālešì) septentrional. L'ouvrage comprend trois parties : 1) une description très sommaire du dialecte: phonologie (y compris une esquisse diachronique du système) ; 2) une étude détaillée (c'est là le cœur du livre) de la structure actancielle de la langue, prenant bien en compte l'ensemble des mécanismes, aussi bien dans leurs manifestations - codage casuel, accord, système de marque personnelles enclitiques... -, que dans leur conditionnement : impact du système TAM (Temps Aspect Mode), de la visée communicative, de la nature des actants (notamment des SAP « Speech act participants »),...; 3) édition, en appendice, du texte recueilli et ayant servi de base à l'étude, accompagné de gloses morphosyntaxiques interlinéaires et d'une traduction anglaise, le tout suivi d'un petit glossaire étymologique. L'analyse actancielle (utilisant les conventions dixoniennes $\mathrm{S}, \mathrm{A}, \mathrm{O}$ ) que l'A. mène est très fouillée, mais difficile à suivre, voire parfois confuse ; elle est aussi limitée par la taille du corpus qui lui sert de base, comme le reconnaît volontiers l'A. (p. 66). Elle permet cependant d'aboutir à un panorama complexe : à l'imperfectif correspond une structure accusative (forte ou faible), au perfectif une structure mixte (accord accusatif, codage casuel ergatif) ou disjointe (p. 59 sq.). On notera quelques erreurs, comme l'interprétation de la « désinence » kurmandjie -im dans dit-im comme un (en)clitique objet (ex. 36b, p. 41, et p. 42). En ce qui concerne la partie diachronique, l'A. semble moins à l'aise : par ex., p. 18 (§ 5.1.3.3.), bo «pour» donné sans étymologie est évidemment à mettre en parallèle avec le persan barâ(-ye) comme bo «frère » (p. 19, ex. G3) avec barâdar. Malgré ces petites réserves, on se réjouira qu'un travail important porte sur le domaine riche et passionnant de l'actance des langues irano-aryennes, dont les premiers défricheurs 
ont été G. Lazard ("Structures d'actance dans les langues irano-aryennes », 1978) et G. Bossong (Empirische Universalienforschung..., 1985). Bibliogr. pp. 91-92.

INDEX

Thèmes : 2.2. Langues vivantes et dialectes

\section{AUTEURS}

VINCENT HACHARD

BIULO - Paris 